\title{
Explanation in Metaphysics?
}

\author{
Johannes Persson
}

Published online: 8 September 2011

(C) The Author(s) 2011. This article is published with open access at Springerlink.com

\begin{abstract}
Arguments from explanation, i.e. arguments in which the explanatory value of a hypothesis or premise is appealed to, are common in science, and explanatory considerations are becoming more popular in metaphysics. The paper begins by arguing that explanatory arguments in science — even when these are metaphysical explanationsmay fail to be explanatory in metaphysics; there is a distinction to be drawn between metaphysical explanation and explanation in metaphysics. This makes it potentially problematic to deploy arguments from explanation in, for instance, metaphysics of science. Part of this problem has its source in that the explanatory concept differs between contexts. The paper discusses a few explanatory concepts and their corresponding arguments from explanation. Towards the end of the paper, I identify two allegedly explanatory arguments in metaphysical discourse by the concluding decisions they give rise to: the rejection of $X$ as a metaphysical fact if $X$ does not explain anything (the argument from explanatory inability) and the rejection of $X$ as a metaphysical fact if $X$ can be non-metaphysically explained (the argument from the non-metaphysically explained). I ask: What kind of concept of explanation do these arguments rely upon, and is that concept suited to the metaphysical task? Two recent examples of these arguments are used as illustration. The preliminary conclusion is that several of the strengths of arguments from explanation in science seem not to be present in metaphysical contexts.
\end{abstract}

Keywords Metaphysical explanation - Scientific explanation · Explanation in metaphysics $\cdot$ Laws of nature $\cdot$ Causation

The word 'explanation' occurs so continually and holds so important a place in philosophy, that a little time spent in fixing the meaning of it will be profitably employed. (Mill 1891/2002, Ch. 12§1, 305)

J. Persson $(\square)$

Department of Philosophy, Lund University, Kungshuset, 22222 Lund, Sweden

e-mail: johannes.persson@fil.lu.se 
Sometimes we infer to the best explanation in science. Sometimes we reject hypotheses on the grounds that their explanatory value is inadequate. Both of these inferential patterns rely on explanatory considerations. Let us refer to reasoning in which the explanatory value of a hypothesis or premise is appealed to as an 'argument from explanation'. 'Arguments from explanation are common in science. Peter Lipton (2004) has made a case for thinking that inference to the best explanation was important to Semmelweis's work on childbed fever; and some of Semmelweis's colleagues found his pet hypothesis inadequate on the grounds that it was unable to explain cases of childbed fever where inoculation by "poison from corpses" was merely a remote possibility (Codell Carter 1983; Persson 2009).

Do arguments from explanation appear in every scientific discipline? Possible exceptions involving pure description and correlation come to mind. What about mathematics? Many explanations in physics, biology, medicine and other sciences build on mathematics, but a distinction can be drawn between an explanation that is (partly) mathematical and an explanation in mathematics (Mancosu 2011; Brinck et al. 2011). We prove propositions, theories and lemmas in mathematics, but do we explain in mathematics? The mathematical explanations we find in physics, biology and medicine do not help us move towards an affirmative answer.

This paper proposes a distinction between metaphysical explanations in science and explanations in metaphysics. Metaphysics can sometimes be put to use in arguments from explanation made in science, in the way mathematics is. In the first two sections of the paper, the work of Ignaz Semmelweis and Pierre Duhem is taken as an illustration of this phenomenon. But is there explanation in metaphysics? Interestingly, it seems that explanatory considerations have been quite influential in the metaphysics of causation and the laws of nature.

In this paper, I identify two explanatory arguments in recent metaphysical discourse by the concluding decisions they give rise to: the rejection of $X$ as a metaphysical fact if $X$ does not explain anything and the rejection of $X$ as a metaphysical fact if $X$ can be non-metaphysically explained. Since I frequently refer to these arguments, I need shorter expressions. I call the first the argument from explanatory inability and the second the argument from the non-metaphysically explained. The argument from explanatory inability builds on the idea that all metaphysical facts explain. It asserts that we can argue from the non-explanatory character of something to its non-metaphysical character. The case I will discuss in the paper is an argument set out by Mumford (2004) against laws as regularities. The argument from the non-metaphysically explained builds instead on the idea that that which has a non-metaphysical explanation is not metaphysical itself. The case I will discuss in this connection is an argument presented by Beebee (2004) concerning causation through absence. Both arguments have peculiar strengths and weaknesses; both are also sensitive to the concept of explanation that accompanies them. They seem unproblematic in many scientific contexts. However, a rather atypical concept of explanation seems to be required if valid, metaphysically relevant conclusions are to be drawn from these two arguments from explanation.

\footnotetext{
${ }^{1}$ Currently, the expression 'argument from explanation' is not much used in this general sense. However, arguments from explanation - so labelled - do appear in philosophical debates on moral realism (e.g. see Blackburn 1991) and studies of the nature of scientific knowledge (Fagan 2011).
} 
The paper does not claim that these two arguments from explanation are salient in philosophical discourse. The main purpose of introducing the arguments is to show that explanations in metaphysics exist and to point to some problems of justification to which this gives rise. On the other hand, arguments from explanation like these two seem to appear in other areas of philosophy. Arguments from explanation in the moral realism debate (e.g. see Blackburn 1991) resemble the rejection of $X$ as a metaphysical fact if $\mathrm{X}$ does not explain anything (the argument from explanatory inability). Non-metaphysical perspectives on scientific explanation and unification (e.g. see Kim 1999; Mäki 2009) build on standpoints related to the rejection of X as a metaphysical fact if X can be non-metaphysically explained (the argument from the non-metaphysically explained).

\section{Metaphysical Explanation and Explanation in Metaphysics}

Talking about explanation in metaphysics is presumably not quite the same as talking about metaphysical explanation. Metaphysical components of scientific explanations may fail to be explanatory in metaphysics. Necessary causes, i.e. causes as necessary conditions, can be considered a metaphysical addition to Semmelweis's explanations of childbed fever in the mid-nineteenth century (see Persson 2009); but necessary causes do not contribute to explanations in metaphysics - at least, not to the same degree as they do in medicine. In general, the causal concept of explanation is common in science but seldom found useful in metaphysics.

The distinction between metaphysical explanation and explanation in metaphysics presupposes that we are able to separate the relevant scientific and metaphysical contexts. This is seldom a problem in the particular case-at least, when metaphysics and the sciences are narrowly conceived. However, it is more of a challenge to say something generally true about this disciplinary boundary.

The usual approach takes its point of departure in the observation that disciplines are often understood in terms of their methods and study objects. The claim that metaphysical enquiry starts where we run out of empirical arguments suggests a methodological difference. It should be noted that this position is fairly common; it does not trivialize the discussion in this paper. However, there is reason not to rely on this line of demarcation in this context: it does not apply to contexts where scientific enquiry is guided by metaphysical explanation.

Would a boundary grounded in the study objects of metaphysics and science be less problematic? I tend to think so, but again I would not like to rule out the possibility that science and metaphysics are occasionally interested in explaining the same things. The metaphysician I am interested in attempts to map the world, not our concepts, and this increases the risk that study objects will overlap somewhat. ${ }^{2}$ This view of metaphysics also fits much of D. H. Mellor's The Facts of Causation and Stephen Mumford's Laws in Nature (to pick just two examples). It might not be the most common conception of metaphysics. It certainly differs, for example, from the metaphysical enterprise P. F. Strawson describes in Individuals: it does not focus on our experiences and concepts - a fortiori it adopts neither a descriptive nor a

\footnotetext{
$\overline{{ }^{2} \text { However, see Duhem's position }}$ in the next section for a different standpoint.
} 
revisionary perspective focus on those experiences and concepts. In this sense, then, the difference between the study objects of metaphysicians and scientists is not trivial.

However, the risk of partial overlap should not be overestimated. Science and philosophy happen to be interested in the same fundamental building blocks of the world (or metaphysical facts, as I will call them in this paper), but very often their interests differ. As a very simple example, consider the fact that the sun is not blue. Both the philosopher and the physicist will judge that this is not a metaphysical fact. The philosopher knows that metaphysical facts cannot have negative constituents (such as the property of not being blue). ${ }^{3}$ The physicist knows that colours are not intrinsic properties of objects such as the sun. But as long as we do not add 'metaphysical' there is no reason to deny that it is a fact that the sun is not blue (and to allow that there have been a reason to deny this if indeed the sun had appeared blue). Whether or not this is a fruitful conceptualization of metaphysics, the use of arguments from explanation to make progress in this direction is what this paper is all about.

\section{Metaphysical Explanation-The Argument from Duhem's Explanations}

Pierre Duhem, an acknowledged philosopher of science, had a controversial view of explanation:

To explain (explicate, explicare) is to strip reality of the appearances covering it like a veil, in order to see the bare reality itself. (Duhem 1906/1991, 7)

Duhem called such explanation "metaphysical explanation". His idea (which is in conflict with what was tacitly assumed in the previous section) was that neither observation nor the experimental laws of physics deal with material reality. Instead, the objects of experimental physics are sensible appearances. It was these appearances that the process of explanation removed, so that theory could proceed "into and underneath them", and seek what was really in bodies. For instance, according to Duhem, sensations of sound have been dealt with in two different ways. The first has given rise to experimental laws of acoustics and a rather abstract set of properties including intensity and pitch. These notions "get us to know sound as it is in relation to us, not as it is by itself in sounding bodies", says Duhem $(1906 / 1991,8)$. The second approach, on the other hand, has amounted to an effort to find out what sound is in sounding bodies:

The latter are to teach us that where our perceptions grasp only that appearance we call sound, there is in reality a very small and very rapid periodic motion; that intensity and pitch are only external aspects of the amplitude and frequency of this motion; and that timbre is the apparent manifestation of the real structure of this motion, the complex sensation which results from the diverse vibratory motions into which we can analyze it. Acoustic theories are therefore explanations. (Duhem 1906/1991, 8)

\footnotetext{
${ }_{3}^{3}$ Of course, not every metaphysician will agree: see Mulligan and Correia (2008), Section 2.2.
} 
Duhem's explanations are of a type that clearly permits arguments from explanation to be used in metaphysical contexts. The characteristic argument appeals to both explanans (C) and explanandum (E); it will look something like this:

The argument from Duhem-explanations

\section{C Duhem-explains E}

\section{2. $\mathrm{C}$ is a metaphysical fact}

In the argument from Duhem's explanations (and, equally, in the further types of argument from explanation that are discussed below), it is presupposed that the explanation is actual. Of course, in most cases, we will not know this. To our knowledge, most explanations are only potential, in the sense that they might be mistaken. ${ }^{4}$ But even potential explanations can make the claim characteristic of the argument from Duhem's explanations.

A concept of explanation such as Duhem's provides us with a new way of stating our project. According to Duhem, to explain is to be engaged in a metaphysical inference that is grounded in its ability to remove of the veil of appearance. If we succeed, a metaphysical fact is established. But in order to do this, we have to deploy metaphysical components (from philosophy or theology) in our explanations. That is one reason why Duhem was against the view that explanation is a central aim of science. The argument in The Aim and Structure of Physical Theory proceeds thus: Duhem first launches the argument from Duhem explanations and then attacks it on the grounds that a Duhemian concept of explanation threatens to make science subordinate to metaphysics. Duhem's observation is very interesting from the point of view of the distinction between explanation in metaphysics and metaphysical explanation. Metaphysical components of scientific explanation are necessary, and perhaps sufficient, for metaphysical explanation in science. However, this does not reveal anything about the status of explanation in metaphysics (but see next footnote). We are only concerned with explanation in science. For Duhem, there is every reason to resist the kind of imperialist metaphysics following in the footsteps of metaphysical explanation. Hence, his perspective on explanation figures mainly as a premise in a reductio in support of scientific-epistemological ${ }^{5}$ anti-realism.

This is probably also one of the reasons why Duhem's approach to explanation has never been taken seriously. It is natural to respond to the argument from Duhem's explanations by questioning the premise. Why take this concept of explanation seriously when it was not the result of a sincere attempt to formulate a viable position in the first place? Duhem may simply be introducing us to a straw

\footnotetext{
${ }^{4}$ For a related view of the actual/potential distinction, as applied to scientific explanation, see Carl G. Hempel's (1970) Aspects of Scientific Explanation.

${ }^{5}$ This qualification is needed. Duhem is not an anti-realist with regard to theology. De Broglie (1953, ix) puts it this way: "It was not that Pierre Duhem, a convinced catholic, rejected the value of metaphysics; he wished to separate it completely from physics and to give it a very different basis, the religious basis of revelation".
} 
man. To the extent that this suspicion is correct, and inasmuch as it has been adopted by Duhem's fellow philosophers of science, I think it has been an unfortunate. Duhem's concept of explanation is not all that uncommon, and I will come back to a few illustrations later on.

\section{The Metaphysical Status of the Explanandum}

Since the argument from Duhem's explanations is introduced in terms of appearance and reality, we have to say something about the consequences not only for that which explains (C), but also for that which is explained (E). There are two ways to go. Either E can be a metaphysical fact itself or it cannot. I will assume that someone who uses the argument from Duhem's explanations would acknowledge that $\mathrm{E}$ can be a metaphysical fact itself. Here are two rather obvious instances where someone following the argument from Duhem's explanations would be interested in saying this:

1. Several potential explanations are tried out; but not one of these turns out to be actual. There is no grounding underneath $\mathrm{E}$. That $\mathrm{E}$ is a metaphysical fact explains why E appears. This kind of self-explanation seems perfectly understandable from a Duhemian perspective on explanation.

2. There might be levels of reality. $\mathrm{E}$ is constituted by $\mathrm{C}$, but already $\mathrm{E}$ is real. $\mathrm{E}$ is not merely an appearance.

This possibility of acknowledging the reality of the explanandum (i.e. recognizing that the explanandum may be a metaphysical fact) makes alternative versions retaining the core idea of the argument from Duhem explanations possible. The most radical version, to deny that $\mathrm{E}$ is a fact at all, is perhaps excluded. The reason is that, in explanatory settings, it is normally presupposed that $\mathrm{E}$ is true, and this might suffice to render $\mathrm{E}$ a fact. I will not go further into this issue here; a similar position is developed in Mellor (1995). But the more moderate possibility - to claim that whereas the explanandum is a fact it is not a metaphysical one-is also open

\section{The Argument from Hung's explanations}

There are philosophers of science who argue for versions of metaphysical explanation where the proposition that "E is not a metaphysical fact" is among the implications of our having a metaphysical explanation. Recently, Edwin H. C. Hung has suggested that many scientific explanations - of regularities and exceptions especially_are of this kind. ${ }^{6}$

\footnotetext{
${ }^{6}$ The wellsprings of Hung's thinking lie in the work of his forerunners Kuhn and Feyerabend and familiar criticisms of deductive models of explanation. From Kuhn, he borrows the focus on the explanation of anomalies by conceptual shift. Among the problems for deductive theories he chooses the eliminativist insight that an empirical law that is only approximately true should not be implied by the explaining theory.
} 
The true driving force of the advancement of science is not Hempel's D-N explanations, as commonly thought. It is reality-vs-appearance explanations that have brought science where it is today. (Hung 2006, 9)

The difference between Duhem's and Hung's position is what really matters here. What happens in explanatory contexts, according to Hung? Typically, one starts with the question "Why E?" Next, any metaphysical claim this question presupposes is rejected. Then metaphysical explanations, allowing us to understand why it was decided, or believed, that E, are proposed. Here is an illustration from astronomy in which an advocate of Kepler's theories explains some apparent irregularities in planetary motions.

Q: "Why do the planets move in retrograde loops?"

$\mathrm{K}$ : "They don't"

Q: "Don't they? It surely appears so."

$\mathrm{K}$ : "You see. The planets move in ellipses around the sun. It is the combination of these elliptic motions of the planets and the earth's own motion that gives rise to the observed phenomenon."

That is, the structure of the metaphysical argument from explanation is:

The argument from Hung's explanations

\section{C Hung-explains E}

2. E is not a metaphysical fact

3. $\mathrm{C}$ is a metaphysical fact

\section{Causal and Non-metaphysical Explanation-the Argument from Mill's Explanations}

For the sake of the argument, and pace Duhem, let us now take it for granted that scientists do explain. This is clearly a widely shared view; but note that the common concept of explanation may differ from Duhem's. Moreover, in addition to Hung's claims, let us grant that explanatory attempts can characterize cumulative phases of scientific inquiry as well. Finally, let us combine this insight with the powerful empiricist tradition in the philosophy of science. In this situation, an alternative concept of explanation is needed - one that does not build on the appearance-reality distinction. Mill is the obvious choice. ${ }^{7}$

What Mill suggests first is that we should distinguish between explanations of individual facts and explanations of uniformities. An individual fact is explained by pointing out its cause - that is, "by stating the law or laws of causation of which its production is an instance" (Mill 1891/2002, Ch12§1, 305). A uniformity is

\footnotetext{
${ }^{7}$ According to David-Hillel Ruben (1990, 112), Mill might have been the first to tackle the problem of finding a workable concept of explanation within an empiricist framework. It should be noted that Ruben's book is interesting in its own right in the context of metaphysical explanation.
} 
explained by pointing out another law, or combination of laws, "of which that law itself is but a case, and from which it could be deduced" (ibid.).

Someone might object that both causes and laws can be understood as entities existing in reality, so that this is precisely the type of metaphysical explanation Duhem and Hung are thinking of. But this is not so, and for two reasons. The first is that it is not obvious in what sense the kinds of explanation Duhem and Hung offer are causal, or whether they have to be causal. In any case, their causal elements will not be the most salient of their features: constitutive elements are likely to be more central. Even if causal and constitutive aspects are combined in some accounts, ${ }^{8}$ Mill's cause-and-effect approach does not have that capacity. A problem similar to Mill's is set out by Bogen and Woodward (1992, 593), who speak rather inelegantly of phenomena producing their data. Again, the traditional cause-and-effect view of causation cannot properly account for the sense in which there is production across these metaphysical levels.

The second, and obvious, reason why Mill's concept of explanation is very different from the metaphysical one is that it comes with a package including suitable empirical concepts of law and causation, thus ensuring that there is no metaphysical leap involved in explaining. For instance:

The Law of Causation [...] is but the familiar truth that invariability of succession is found by observation to obtain between every fact in nature and some other fact which has preceded it, independently of all considerations respecting the ultimate mode of production of phenomena, and of every other question regarding the nature of 'Things in themselves'. (Mill 1891/2002, Ch 5 §2, 213)

Instead of removing the "reality of the appearances covering it like a veil, in order to see the bare reality itself", as Duhem had it, Mill's take is that "what is called explaining one law of nature by another, is but substituting one mystery for another, and does nothing to render the general course of nature other than mysterious" (Mill 1891/2002, Ch11§6, 310).

So, is there any metaphysical lesson to be learned from Mill's non-metaphysical concept of explanation? Well, if one focuses on "substituting one mystery for another" it may be claimed that there is a metaphysically relevant argument from explanation here as well.

The argument from Mill's explanations

\section{C Mill-explains E}

2. There is (still) no reason to assume that the metaphysical status of $\mathrm{C}$ and $\mathrm{E}$ differ

The argument from Mill's explanations is more artificial than the previous two basic forms of explanatory argument. The relation between explanation and metaphysical status is much weaker. The bracketed "(still)" is of some importance here. The argument from Mill's explanations does not seem to bar independent evidence pointing in another metaphysical direction.

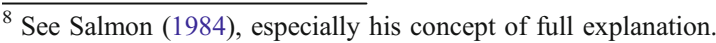




\section{Indeterminate Cases-Some Contemporary Additions to the Concept of Explanation}

Causal approaches like Mill's remain pervasive. This is not the proper place for anything more than a brief characterization of later approaches, but because Hung is not a mainstream philosopher of explanation, it is worth pausing for a moment to give a flavour of contemporary causal theory. A concept of explanation with a better claim to being the received view is:

To explain an event is to provide some information about its causal history.

(Lewis 1986, 217)

Only a few decades ago Hempel's (1970) models of explanation would have been the default choice. There are, of course, several competitors on the market, and in the light of the previous distinction one might wonder whether these contemporary concepts of explanation are non-metaphysical. It is not easy to tell. What it is safe to say is that the metaphysical dimension which preoccupied Duhem and Mill is less pronounced nowadays. It has already been shown that the metaphysical implications of the previous concepts differ a good deal, so anyone using the contemporary concepts of explanation in metaphysical contexts has to think twice about what kind of inferences they license.

\section{Transferring Concepts of Explanation to Metaphysics}

It is time to turn to some metaphysical applications, i.e. arguments from explanation in metaphysical contexts. The questions how explanatory arguments are used, and whether this use is justified, are now in focus. A pair of typical arguments will be presented. They appear in two recently published works on metaphysics. I will give the actual examples later. I will say something about the structure of the arguments, as I understand them, first.

7.1 The Argument from Explanatory Inability (Rejection of X as a Metaphysical Fact if X Does Not Explain Anything)

The first kind of argument I have selected takes the form of a modus tollens:

The argument from explanatory inability (rejection of $\mathrm{X}$ as a metaphysical fact if $\mathrm{X}$ does not explain anything) (original)

1. If $\mathrm{C}$ is a metaphysical fact, then $\mathrm{C}$ explains

2. C does not explain

3. C is not a metaphysical fact

To anyone who shares ground with Duhem and Hung, this will look like a sensible argument. It should also look sensible to anyone else who stresses the ontic aspects of explanation (i.e. that explanatory relevance is an objective feature of the 
world). ${ }^{9}$ The main problem is that the second premise - the claim that $\mathrm{C}$ does not explain - is difficult to establish. $\mathrm{C}$ might be a candidate explanation not only of $\mathrm{E}_{1}$, but also $\mathrm{E}_{2} \ldots \mathrm{E}_{\mathrm{n}}$. How, then, can we ever know that $\mathrm{C}$ does not explain?

At this stage, it is tempting to introduce a further metaphysical relation between $\mathrm{C}$ and what it explains - a relation to be added to the explanatory relation between them. Let us call this metaphysical relation grounding. With this postulated relation in place, we can conveniently reformulate the argument thus:

The argument from explanatory inability (grounding)

1. If $\mathrm{C}$ is a metaphysical fact grounding $\mathrm{E}$, then $\mathrm{C}$ explains $\mathrm{E}$

2. $\mathrm{C}$ does not explain $\mathrm{E}$

\section{3. $\mathrm{C}$ is not a metaphysical fact grounding $\mathrm{E}$}

What kind of concept of explanation do we need to assume in order for this argument to be justified? Well, can we rest content with Mill's conception of explanation? No, that would be deeply problematic because it has both a causal and a non-metaphysical character. The problem with the causal part is that $\mathrm{C}$ can be a metaphysical fact (and in our sense ground) without being a cause, so premise 1 is sometimes false. This will be a problem for causal accounts of explanation in general. Since several of the contemporary concepts of explanation are of this kind, there is indeed a problem with the applicability of the argument from explanatory inability. The non-metaphysical character of Mill's concept generates an even more obvious problem. The argument from Mill's explanations bars inferences from explanation to metaphysical facts (no metaphysics in, no metaphysics out); but the argument from explanatory inability builds on precisely this inference. Since many contemporary approaches to explanation are epistemic rather than metaphysical, this limits the applicability of this argument from explanation even more.

A metaphysical concept of explanation that is not merely causal seems to be needed if the argument from explanatory inability is to be valid. In addition, the relation of grounding seems to imply that a feasible concept of explanation will allow both explanans and explanandum to be facts. So, Hung's concept of explanation is also problematic in this context. But if a satisfactory concept of explanation can be provided, we shall have a strong argument from explanation on our hands. On the plausible assumption that the relation of grounding entails that we have Duhem's metaphysical explanation, premise 1 is true and the argument is valid. With these preliminaries in place, we know quite well what to be looking for in applications of the argument.

\subsection{The Application-Mumford's Laws in Nature}

In Laws in Nature, Stephen Mumford examines the metaphysics of laws of nature. He begins by describing the shared temptation of philosophers and scientists to find out whether there are such things as laws of nature, and how they are related to the

\footnotetext{
${ }^{9}$ Salmon would be one example. Provided that metaphysical facts enter causal networks, these facts will be relevant to the causal structure of the world and (so) explanatory.
} 
regularities (and sometimes irregularities) that we are often able to find in nature. He formulates the theory of laws as the view that the world contains certain fundamental truths, facts or things that explain why there are natural regularities (Mumford 2004, 1).

Throughout Laws in Nature, Mumford argues against this "theory of laws" by eliminating various suggestions as to what the laws are, and by suggesting that necessary connections in nature other than laws can do any required work. My purpose, in this context, is purely illustrative, and therefore I will concentrate on only one of these contexts of argumentation: the reason why regularities fail. The argument from explanatory inability plays an important role in this context. Mumford clearly has the right kind of concept of explanation in place for the argument:

The best account of explanation, in the current case, would be that the true explanation is one that invokes some kind of entity or existent that is a metaphysical grounding of our explanans. (Mumford 2004, 3)

Here, and at various other places, I make use of a metaphysical notion of explanation in which some phenomenon explains another if it provides a metaphysical ground of it. This is the notion of explanation that I find best suited to the current investigation. (Mumford 2004, 208)

But although Mumford is on the right track, it should be noted that, of these two versions, the second is clearly best suited for the argument. The reason is that the first formulation invites a situation where only the explanans (C) is explained by citing the metaphysical fact grounding it. The relation between $\mathrm{C}$ and $\mathrm{E}$ is not determined by the account Mumford gives in the first passage quoted. It could therefore be, for instance, Millian. What grounding does in that case is still explanatorily relevant. It secures the truth of $\mathrm{C}$. But that only takes us some distance towards an actual explanation. It does not in any way ensure that the explanation of E will be an unveiling in Duhem's sense. This problem does not recur in the second passage quoted, where $\mathrm{C}$ stands in the relation of grounding to $\mathrm{E}$.

Let us now examine one point in Laws in Nature at which the argument from explanatory inability is put to work. The first time is at the very beginning of the book, where Mumford introduces the notion that a law is entirely constituted, or exhausted, by its instances. Nothing makes it the case that water boils at $100^{\circ} \mathrm{C}$; the law is simply the brute fact that it does. Mumford notes:

A law cannot non-trivially explain the regularity if it is nothing more than that regularity, for that would be a case of something explaining itself. (Mumford 2004, 3)

The charge against self-explanations is well known. Hempel discusses the problems early on in Aspects of Scientific Explanation in connection with his idea that explanations show why something was to be expected. And it is clearly also problematic to combine the idea of self-explanation with ideas about progress in unification, or with causation. But in connection with the rejection of $X$ as a metaphysical fact if $X$ does not explain anything (the argument from explanatory inability), these concepts of explanation have already been ruled out. Mumford should have based the charge on his own concept of explanation; his actual take on the question is inefficient. 
Moreover, it is not obvious that the issue is only the apparent problem that an unsuitable concept of explanation is being relied upon. It could be that this kind of "self-explanation" is not ruled out by the concept of explanation Mumford explicitly defends. Then, there would be a substantial problem at this point. Indeed, there is some reason to suspect that this is the case. In connection with the discussion of the metaphysical status of the explanandum in the argument from Duhem's explanations, it was observed that a Duhemian concept of explanation is consistent with the fact that $\mathrm{p}$ can explain the appearance of $\mathrm{p}$. Mumford's concept resembles Duhem's. Now, of course, Mumford does not talk about the difference between appearance and reality. However, his position seems to trade on a somewhat similar difference between two kinds of regularity: regularity as association and regularity as law. To me, we cannot rule out the possibility that, in metaphysics, the latter might explain the former. It is not the same as - but then, nor either is it very different from-the account of metaphysical explanation as truthmaker explanation currently in vogue (e.g. see Betti 2010).

Metaphysicians applying arguments from explanation in the form of the argument from explanatory inability must look carefully at their concepts of explanation. Different concepts of explanation license very different conclusions.

\subsection{The Argument from the Non-metaphysically Explained (Rejection of X as a Metaphysical Fact if X Can Be Non-metaphysically Explained)}

The second argument to be examined has the following structure:

The argument from the non-metaphysically explained (rejection of $\mathrm{X}$ as a metaphysical fact if $\mathrm{X}$ can be non-metaphysically explained)

1. C explains $\mathrm{E}$

2. $\mathrm{C}$ is not a metaphysical fact

\section{E is not a metaphysical fact}

What kind of concept of explanation does this argument need? Let us first try Mill's causal and non-metaphysical concept. To begin with, we can note that there are some problems with the causal part. Often, our knowledge of an object's causal roles is presumed to be our best reason to regard it as real, in the metaphysical sense intended in this paper. Nancy Cartwright (1983, Essay 4) and Ian Hacking (1983, Ch. 1) are well-known advocates of this position. So, where a causal concept of explanation is concerned most contemporary philosophers would not hold the conjunction of 1 and 2 in the argument from the non-metaphysically explained to be true. ${ }^{10}$ What about the non-metaphysical part of Mill's concept of explanation? The argument is not as clearly disharmonious with this part. That $\mathrm{C}$ explains $\mathrm{E}$ suggests that $\mathrm{E}$ is not "more" metaphysical than $\mathrm{C}$ - which, together with 2, might be thought to support (weakly) the conclusion in 3. But the argument is clearly not valid. Independent evidence can easily overthrow the conclusion.

\footnotetext{
${ }^{10}$ As we have seen, however, Mill would perhaps be prepared to do so, given the non-metaphysical connotations of his causal concept.
} 
Let us try Duhem's explanations (or Hung's explanations) instead: C has higher metaphysical status, or rank, than E. If $\mathrm{C}$ is not a metaphysical fact, nor is E. But both the argument from Duhem's explanations and the argument from Hung's explanations, as presented, yield an inconsistency between the two premises in the argument from the non-metaphysically explained. According to Duhem's and Hung's explanations, premise 1 entails that $\mathrm{C}$ is a metaphysical fact. A more suitable phrasing of the argument may be the following:

The argument from the non-metaphysically explained (revised to avoid inconsistency)

\section{C explains E}

2. $\mathrm{C}$ is not a metaphysical fact of kind $\mathrm{K}$

3. $\mathrm{C}$ is a metaphysical fact

4. E is not a metaphysical fact of kind $\mathrm{K}$

Notice that this argument is not valid in all possible applications - not even with Duhem's concept of explanation. If levels in nature are allowed, then, despite the fact that there are explanatory relations between levels, entities at different levels will normally belong to different kinds. For instance, populations constitute one ecological level and organisms and their interactions belong to the level below. Populations can be dense, individuals and their interactions cannot, and so on. But here is the interesting part, as far as I am concerned: we are better off when, and as long as, only the two levels of appearance and reality are recognized. We have come across only one situation so far where $\mathrm{E}$ is a metaphysical fact in spite of belonging to the realm of appearance: the situation where naïve realism is true. However, since $\mathrm{C}=\mathrm{E}$ in that context, this result is unproblematic with regard to the present argument. I conjecture that, with the exception of levels in nature, the revised version of the argument from the non-metaphysically explained is valid when the concept of explanation is Duhem's explanation (or Hung's explanation). Hence, in the choice between a non-metaphysical and a metaphysical concept of explanation, it would appear to be beyond doubt that a metaphysical concept is preferable if we wish to draw metaphysically relevant conclusions from the argument from the non-metaphysically explained.

\subsection{The Application-Beebee on Causation and Nothingness}

Experience teaches us that causation involves absences, or failures to happen or act, almost as often as it involves things being present, happenings or acts: Kim has no children because she used contraception; and the orchid died because I did not give it water. This is not a reflection of plain casualness. On closer examination, in a lot of positive causation, the causes are absences. Chopping off someone's head causes death, but it does so through an absence, since chopping off the head shuts down vital processes. ${ }^{11}$ Moreover, causation by absences does not only belong to folk science. In biology, relations are often expressed in the negative: gazelles that do not run fast enough do not survive. Selection explanations, in particular, often rely on a rule, or

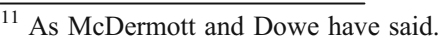


law, that is negative. ${ }^{12}$ Causation, furthermore, is often reported where predators prevent prey behaviour. Have a look at the following passage from an inquiry into the costs of responding to predators for 15 species of anuran tadpoles:

Behavioural responses, such as habitat shifts and decreased foraging to avoid detection by predators, often cause a decline in the rate of food consumption and may therefore entail a fitness cost. (Van Buskirk 2000, 2814)

A causal relation, like other relations, requires that which is related to exist. Absences cannot be the relata of a causal relation (unless negative entities exist, which we have good reason to deny). The kind of causal theory required to make these cases genuinely causal has to build on components other than causes and effects, like Mellor's theory in The Facts of Causation.

The crucial point for Helen Beebee and other advocates of the cause-and-effect view is whether someone who believes in the cause-and-effect view of causation can handle apparent cases of absences in causation in a way that is compatible with our experience of causation. Can we, for instance, utilize Donald Davidson's (1967) distinction between causation and causal explanation? Beebee follows this path in an effort to eliminate the non-metaphysically explained as a metaphysical fact:

If absences are to figure in causal explanations without doing any causing, there must be a distinction between causation and causal explanation: Some causal explanations cannot be reports of causation. (Beebee 204, 302)

Are there causal explanations that do not report causation? Plug in Lewis's "causal" view of explanation: "To explain an event is to provide some information about its causal history." Of course, the causal history part of this formulation is not immediately useful if we interpret causal history narrowly. In that case, it will only be (previous) causes that count, and that is of no use in solving this puzzle. But the preceding part-some information about this causal history - may be more promising. Several well-known discussions in the literature on causation provide examples of causal information that seem to transcend the citation of a cause. A common example is the following:

(A) Oswald's shot caused JFK's death

(B) JFK died because Oswald shot him

(C) JFK died because somebody shot him

Imagine that we are advocates of the cause-and-effect view. Then, (A) may be a true causal report. (B) and (C), however, will probably not be treated this way. The explanans in (B) and the explanans in (C) do not stand in the right kind of causal relation to the explanandum for this to happen - the explanans is in neither case the cause of the explanandum. Still both (B) and (C) provide some true information about the causal history of Kennedy's death (Beebee 2004, 304). Of course, much more needs to be said if we are to understand how (A), (B) and (C) connect, but the image is clear enough to introduce the idea.

If the idea works out in cases of positive causation, such as the death of Kennedy, then similarly, we might ask, Could it work in cases with absences? Say that a, b and c cause $d$. To give the information that $g$ was no part of the situation is to reveal

${ }^{12}$ Compare Bird (2007). 
something (possibly relevant) about the causal history of $\mathrm{d}$. When I say that the orchid died because I did not water it, I reveal something that is possibly relevant about the death of my orchid. When I say that the orchid died because I did not water it, I communicate a message about the causal structure in worlds where I water the orchid - "namely, that the causal processes that ensued at those worlds did not cause (or perhaps might not have caused)" (Beebee 2004, 305) the orchid's death. The analogue between the Kennedy murder and the orchid's death is not perfect given to Lewis's concept of explanation. Lewis's view speaks of information about causal history. What we are offered in this case are facts about what goes on in other worlds. The situation is substantially different from what was on offer in the positive case above. For purposes of illustration, however, I am happy to continue. So, what kind of conclusion does this causal explanation license?

Recollect the relevant argument from explanation - the argument from the nonmetaphysically explained in revised form. This pattern can arguably be applied to the story above. What we have, in Beebee's discussion of absences in causation, might be the argument:

$1^{*}$.(Causal history, C) The fact that I didn't water the orchid was not among the actual causes of my orchid's death, but in close worlds where I do water the orchid the causal processes are such that the orchid does not die

2*. The orchid died because I didn't water it is Lewis-explained by $\mathrm{C}$

3*. C does not express actual metaphysical causation

4*. C expresses metaphysical facts

5*. The orchid died because I didn't water it is not a case of actual metaphysical causation

Here, $2 *$ follows from $1 *$ together with Lewis's concept of explanation. However, as we saw in 7.3, the entire argumentative structure is modelled on a metaphysical concept of explanation. And the relation Lewis explains does not seem to be metaphysical. If Lewis explains is rather like the relation Mill explains, which I think it is, then we need, first, to remove conclusion $4 *$. It should be removed since the concept of explanation only talks about information, and whether or not a case can be made for holding that information is a fact, it will not be a metaphysical fact. But above all the argument now faces the problem that it is much too weak to give us a good ground to draw conclusion $5 *$. The premises are compatible with the explanandum, the orchid died because I didn't water it, being genuinely causal. While this interpretation of Lewis explains justifies our belief in the truth of the premises, the argument is obviously not valid. We would very much like to read Lewis explains in a different way. We would like to read it so that information does not do the work, and we might like to read it so that to Lewis explain something is to cite one or several of its causes.

Instead, then, assume that Lewis explains is indeed metaphysical. Now, the structure is valid, but the truth of the premises becomes a more doubtful issue. Most importantly, whether or not $2 *$ follows from $1 *$ is unclear. In order to be metaphysical, the concept of explanation must be pushed in the direction of causation rather than mere historical information. But this makes the distance between $1^{*}$ and $2 *$ greater; it also makes the conjunction of $2 *$ and $3 *$ less plausible. It seems that, with a metaphysical concept of explanation, an important point is made by Mellor's $(1995,130)$ original and rhetorical question: "... how can facts explain other facts causally without causing them?" 
This question, which is easily answered if we presuppose that causal explanation does not have to go all the way down to the metaphysical level, is much harder when that is exactly what one has to do. The concepts that make your arguments go through are sometimes the very concepts that do not license the relevant conclusions.

\section{Disciplines, Explanatory Relations and Explanatory Relata}

A variety of arguments from explanation-arguments, that is to say, appealing to explanatory value - seems to be deployed in science and philosophy. Inference to the best explanation is a well-known version. This paper has identified two other varieties of argument from explanation: the argument from explanatory inability (resulting in the rejection of $X$ as a metaphysical fact if $X$ does not explain anything) and the argument from the non-metaphysically explained (resulting in the rejection of $X$ as a metaphysical fact if $X$ can be non-metaphysically explained). The first of these builds on the idea that all metaphysical facts explain. It asserts that we can argue from the non-explanatory character of something to its non-metaphysical character. The second builds instead on the idea that that which has a non-metaphysical explanation is not metaphysical itself.

An initial problem, which I discuss in the paper, occurs if we want to argue from such findings to the conclusion that explanatory appeals appear within a particular discipline. The problem is that a disciplinary component may be explanatory outside its disciplinary boundary only. Mathematics is perhaps an example here. There are mathematical explanations in science, but it is not clear whether all of them are explanations in mathematics. Brinck et al. (2011), for instance, argue that there are no explanations in mathematics.

A similar boundary can be drawn between metaphysical explanation and explanation in metaphysics. Metaphysical explanation in science depends on an interdisciplinary relation given in which a metaphysical building block, such as necessary cause, is found relevant and acceptable as explanans. But the presence of metaphysical explanations does not prove the existence of explanations in metaphysics. However, it seems that enquiries such as Mumford's (2004) and Beebee's (2004) are examples of argument from explanation in metaphysics.

Explanation in metaphysics gives rise to an interdisciplinary problem. It seems to presuppose that a suitable relation of explanation is added to metaphysics. The desire to ensure that metaphysical explanation in science and explanation in metaphysics are fruitfully related gives us a strong reason to adopt an explanatory relation similar to that in science. However, that adoption generates a justificatory problem. Does a scientifically inspired explanatory relation make valid the kinds of argument from explanation in metaphysics we currently rely upon? Hence, explanation in metaphysics gives rise to two questions. What kind of concept of explanation do these arguments rely upon, and is that concept suited to the metaphysical task?

Acknowledgements I am grateful to a number of people for discussions that have been important when I was writing this paper. Robin Stenwall and Henrik Thorén have influenced my views on metaphysics and interdisciplinary relations, respectively. My discussions with Nils-Eric Sahlin have been instrumental in shaping my thought on both the mathematics-metaphysics comparison and the distinction between metaphysical explanation and explanation in metaphysics. Audiences at seminars held at the Center for 
Philosophy of Science, University of Pittsburgh (2007) and Department of Philosophy, Lund University (2007 and 2008) have also been helpful; they made me realize early on that parts of my first take on this issue had to be reconsidered. Special thanks go to Paul Robinson and one of Metaphysica's anonymous referees for a number of very helpful comments and suggestions. Grants from The Swedish Research Council, grant number 2007-2270, and FORMAS, 2008-2018, made the writing of this paper possible.

Open Access This article is distributed under the terms of the Creative Commons Attribution Noncommercial License which permits any noncommercial use, distribution, and reproduction in any medium, provided the original author(s) and source are credited.

\section{References}

Beebee H (2004) Causation and nothingness. In: Collins, Hall, Paul (eds) Causation and counterfactuals. MIT Press, Cambridge Mass.

Betti A (2010) Explanation in metaphysics and Bolzano's theory of ground and consequence. Logique et Analyse 56:28-316.

Bird A (2007) Selection and explanation. In: Persson J, Ylikoski P (eds). Rethinking Explanation Boston Studies in the Philosophy of Science, vol. 252. Springer, Dordrecht.

Blackburn S (1991) Just causes. Philosophical Studies 61:3-17.

Bogen J, Woodward J (1992) Observations, theories and the evolution of the human spirit. Philosophy of Science 59(4):590-611.

Brinck I, Hermerén G, Persson J, Sahlin N-E (2011) Why metaphysicians do not explain. In: Reboul A (ed.) Philosophical papers dedicated to Kevin Mulligan. Université de Genève, http://www. philosophie.ch/kevin/festschrift/

Cartwright N (1983) How the laws of physics lie. Clarendon Press, Oxford.

Codell Carter K (1983) Translator's introduction. In: M Somoza (ed) Semmelweis I The etiology, concept, and prophylaxis of childbed fever. The University of Wisconsin Press, Madison.

Davidson D (1967) Causal relations. Journal of Philosophy 64:691-703.

de Broglie L (1953) Pierre Duhem's life and work. In: Duhem P (1954) The Aim and Structure of Physical Theory, Princeton University Press, pp. v-xiii.

Duhem P (1906/1991) The aim and structure of physical theory. Princeton University Press, Princeton NJ.

Fagan M B (2011) Is there collective scientific knowledge? Arguments from explanation. Philosophical Quarterly 61:247-269.

Hacking I (1983) Representing and intervening. Cambridge University Press, Cambridge.

Hempel CG (1970) Aspects of scientific explanation. Glencoe, Oxford.

Hung, E H-C (2006) Beyond Kuhn: scientific explanation, theory structure, incommensurability, and physical necessity. Ashgate Publishers, Aldershot.

Kim J (1999) Hempel, explanation, metaphysics. Philosophical Studies 94:1-20

Lewis D (1986) Postscripts to 'Causation'. In his: Philosophical Papers, vol II. Oxford University Press, Oxford, pp 172-213.

Lipton P (2004). Inference to the best explanation. Routledge, London.

Mäki U (2009) Economics imperialism: concept and constraints. Philosophy of the Social Sciences 39: 351-380.

Mancosu P (2011) Explanation in mathematics. In: Zalta E (ed.) The Stanford Encyclopedia of Philosophy (Summer 2011 Edition), URL $=<$ http://plato.stanford.edu/archives/sum2011/entries/ mathematics-explanation/>

Mellor D H (1995) The facts of causation. Routledge, London.

Mill J S (1891/2002) A system of logic. University Press of the Pacific, Honolulu.

Mulligan K and Correia F (2008) Facts. In: Zalta E (ed.) The Stanford Encyclopedia of Philosophy (Winter 2008 Edition), URL=<http://plato.stanford.edu/archives/win2008/entries/facts/>.

Mumford S (2004) Laws in nature. Routledge, London.

Persson J (2009) Semmelweis's methodology from the modern stand-point. Studies in History and Philosophy of Biological and Biomedical Sciences 40(3):204-209.

Ruben D-H (1990) Explaining explanation. Routledge, London.

Salmon W (1984) Scientific explanation and the causal structure of the world. Princeton University Press, Princeton NJ.

Buskirk J Van (2000) The costs of an inducible defense in Anuran larvae. Ecology 81(10): 2813-2821. 